\title{
Urban increments of gaseous and aerosol pollutants and their sources using mobile aerosol mass spectrometry measurements
}

Miriam Elser et al.

Correspondence to: Imad El-Haddad (imad.el-haddad@psi.ch) and André S. H. Prévôt (andre.prevot@psi.ch)

The copyright of individual parts of the supplement might differ from the CC-BY 3.0 licence. 
Table S1: Correlation coefficient $\left(R^{2}\right)$ between the spatial distributions of all sources and components.

Tartu:

\begin{tabular}{|c|c|c|c|c|c|c|c|c|c|c|c|c|}
\hline$R^{2}$ & $\mathrm{HOA}$ & BBOA & RIOA & $\mathrm{OOA}$ & $\mathrm{SO}_{4}$ & $\mathrm{NO}_{3}$ & $\mathrm{NH}_{4}$ & $\mathrm{Cl}$ & $\mathrm{eBC}$ & $\mathrm{CO}_{2}$ & $\mathrm{CO}$ & $\mathrm{CH}_{4}$ \\
\hline HOA & & 0.02 & 0.32 & 0.02 & 0.04 & 0.09 & 0.16 & 0.10 & 0.61 & 0.59 & 0.58 & 0.06 \\
\hline BBOA & & & 0.47 & 0.05 & 0.28 & 0.20 & 0.16 & 0.47 & 0.03 & 0.01 & 0.10 & 0.11 \\
\hline RIOA & & & & 0.08 & 0.35 & 0.14 & 0.22 & 0.39 & 0.24 & 0.17 & 0.28 & 0.07 \\
\hline $\mathrm{OOA}$ & & & & & 0.12 & 0.09 & 0.12 & 0.21 & 0.01 & $<0.01$ & $<0.01$ & 0.01 \\
\hline $\mathrm{SO}_{4}$ & & & & & & 0.07 & 0.10 & 0.12 & 0.03 & 0.02 & 0.08 & 0.03 \\
\hline $\mathrm{NO}_{3}$ & & & & & & & 0.60 & 0.28 & 0.08 & 0.08 & 0.11 & 0.11 \\
\hline $\mathrm{NH}_{4}$ & & & & & & & & 0.24 & 0.09 & 0.05 & 0.11 & 0.10 \\
\hline $\mathrm{Cl}$ & & & & & & & & & 0.07 & 0.03 & 0.11 & 0.13 \\
\hline $\mathrm{eBC}$ & & & & & & & & & & 0.77 & 0.75 & 0.08 \\
\hline $\mathrm{CO}_{2}$ & & & & & & & & & & & 0.78 & 0.08 \\
\hline $\mathrm{CO}$ & & & & & & & & & & & & 0.14 \\
\hline $\mathrm{CH}_{4}$ & & & & & & & & & & & & \\
\hline
\end{tabular}



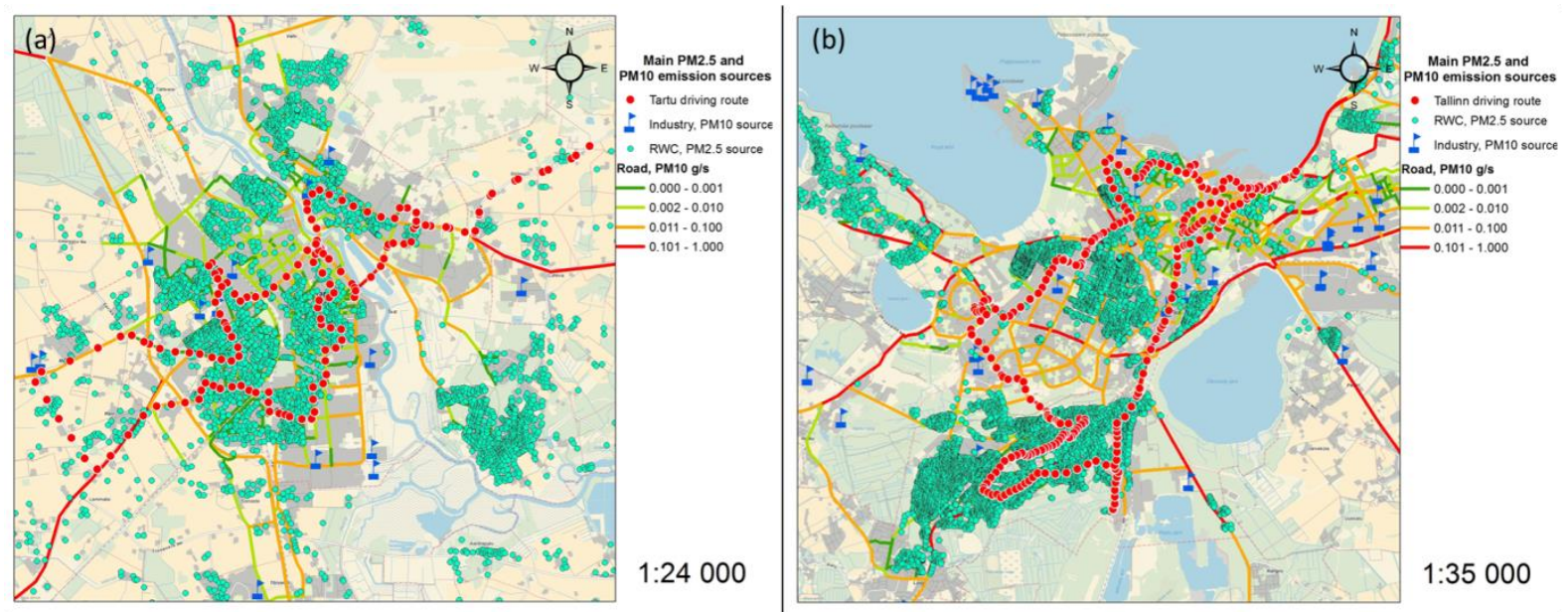

Figure S1: Emission maps for (a) Tartu and (b) Tallinn. Green dots indicate residential wood combustion sources, blue markers indicate industrial sources (mainly local boiler houses) and the color of the main streets represents the traffic emission rates. 


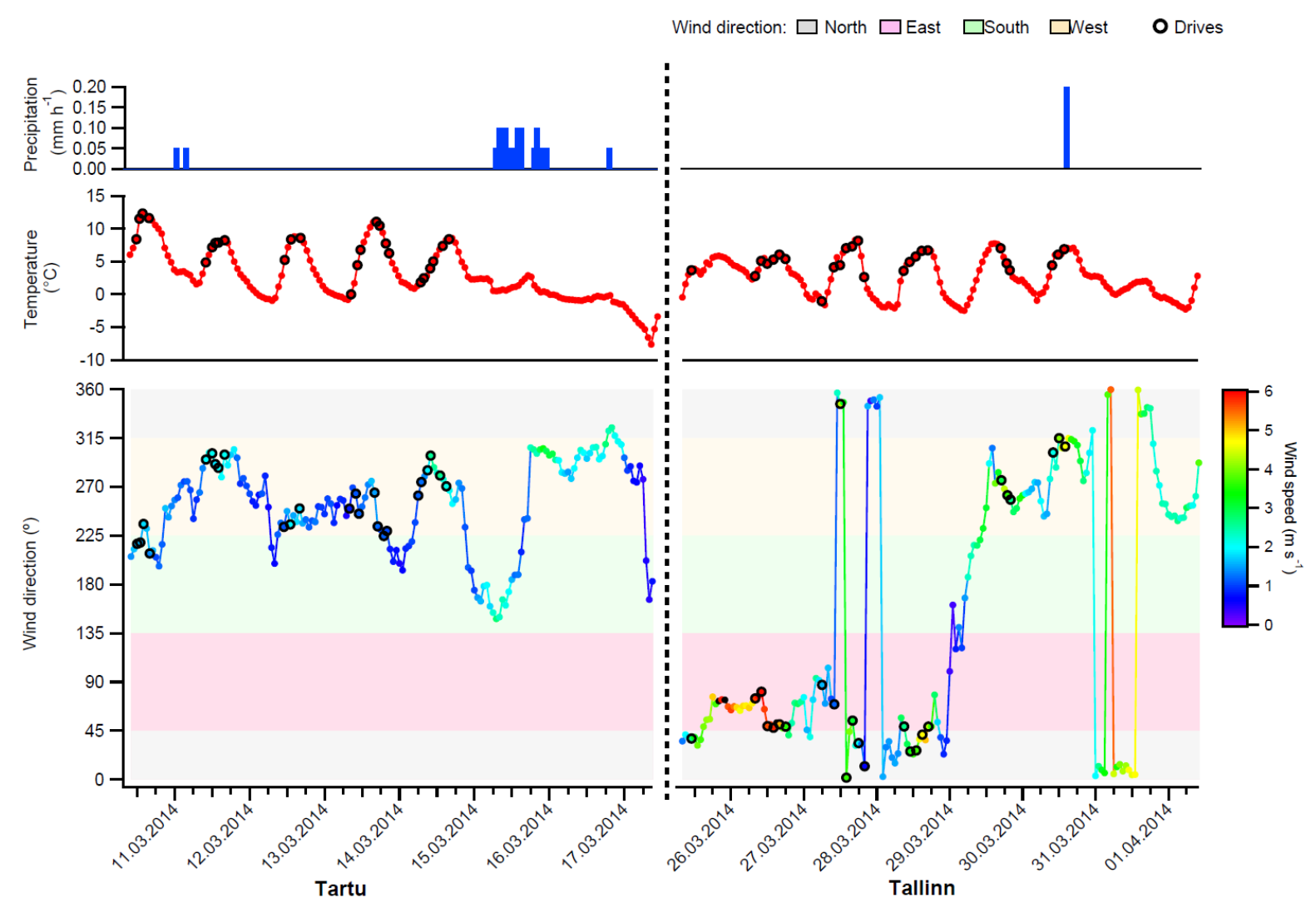

Figure S2: Meteorological conditions during measurements periods in Tartu (data from the Tartu monitoring station) and Tallinn (data from the Zoo monitoring station). 


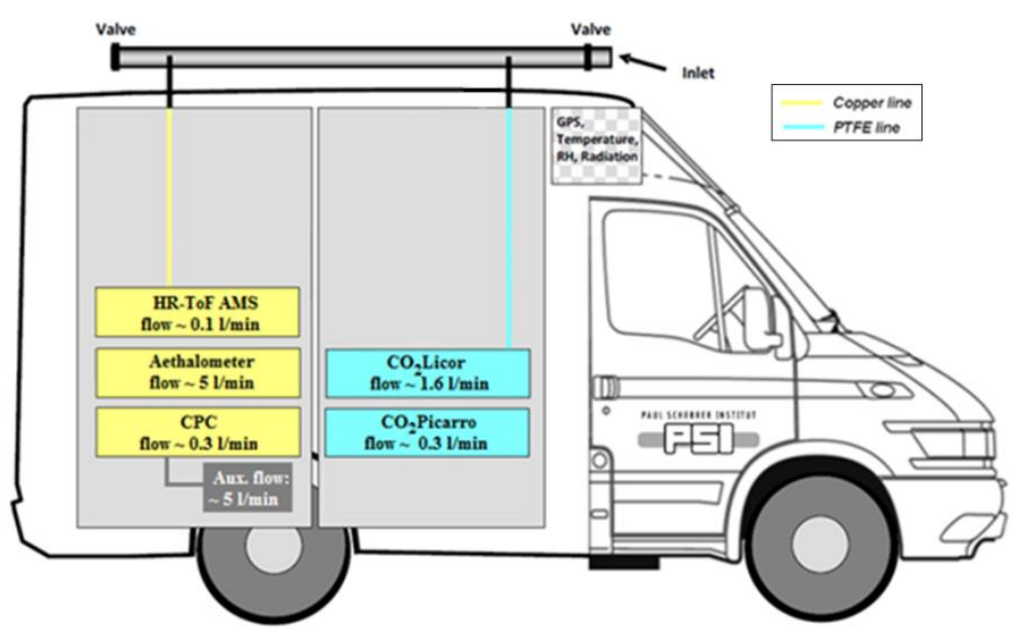

Figure S3: Schematic of the mobile laboratory instrumental set-up. 


\section{SI for section 2.4.2 eBC source apportionment:}

The choice of the wavelengths and of the angstrom exponents used in this work are based on the findings in Zotter (2015), where radiocarbon $\left({ }^{14} \mathrm{C}\right)$ measurements of elemental carbon (EC) are combined with Aethalometer data to determine the Ångström exponents characteristic for wood burning $\left(\alpha_{\mathrm{wb}}\right)$ and traffic $\left(\alpha_{\mathrm{tr}}\right)$ emissions. The best $\alpha$ values were evaluated by fitting the source apportionment results of the Aethalometer (in particular $\left.\mathrm{BC}_{\mathrm{tr}} / \mathrm{BC}\right)$ against the fossil fraction of $\mathrm{EC}\left(\mathrm{EC}_{\mathrm{f}} / \mathrm{EC}\right)$ derived from ${ }^{14} \mathrm{C}$ measurements. The best fitting $\alpha_{\mathrm{tr}}=0.9$ and $\alpha_{\mathrm{wb}}=1.68$ were obtained, when using the attenuation measured at 470 and $950 \mathrm{~nm}$.

Other wavelength combinations were also tested but in all cases, especially when $370 \mathrm{~nm}$ was used, the residuals of the fit were worse. Moreover it is known that the $370 \mathrm{~nm}$ channel of the Aethalometer is more sensitive to artefacts, including response to light absorbing SOA and the adsorption of VOCs on the filter. 
(a)

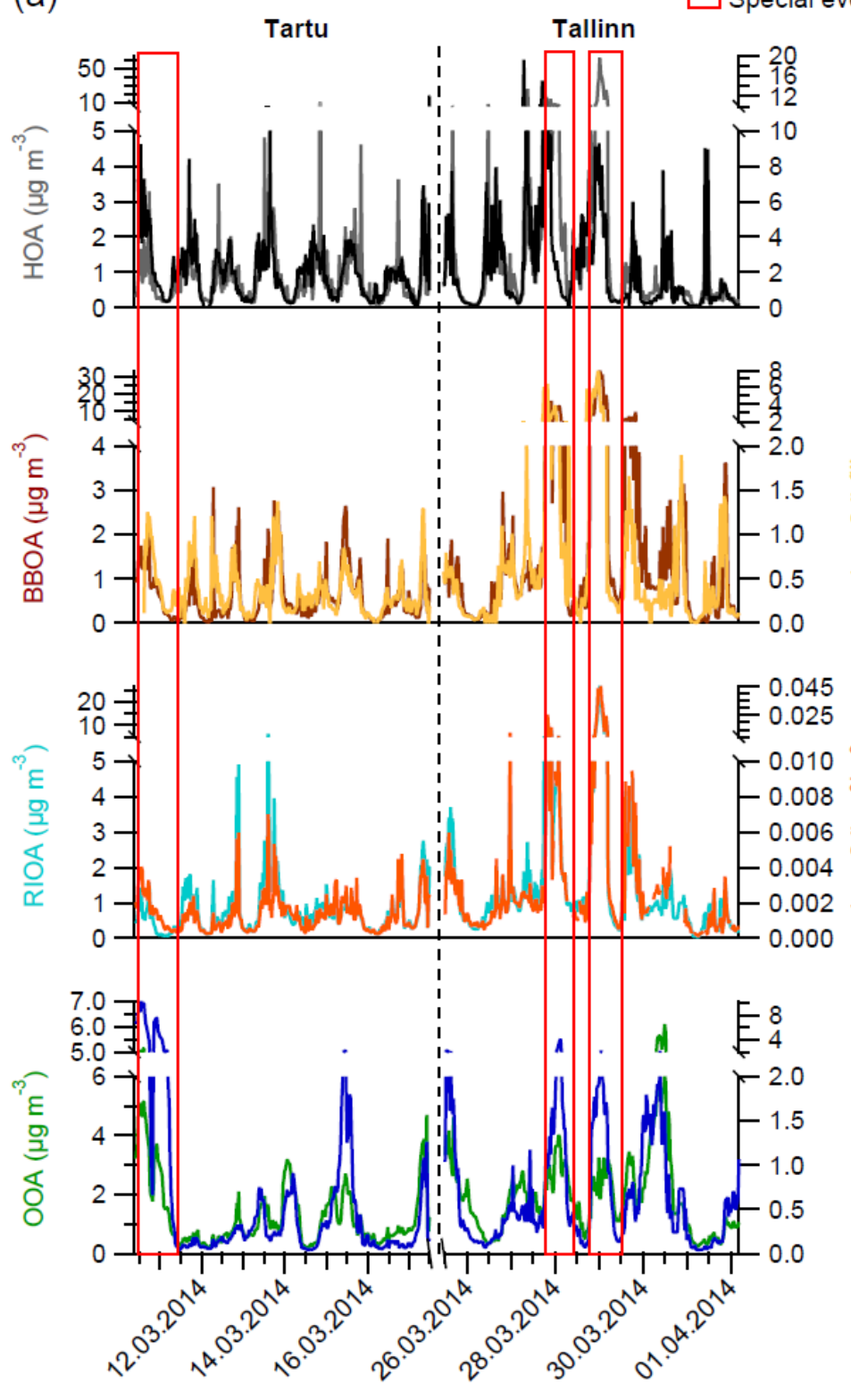

(b)
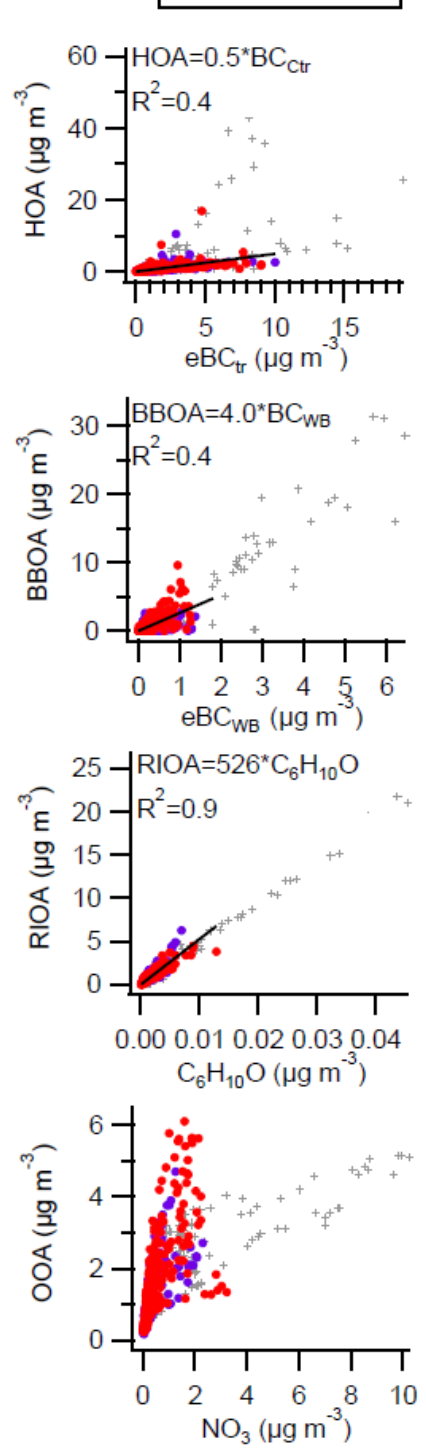

Figure S4: (a) Temporal evolution of the OA sources (left axis) and the external tracers (right axis) over the full measurements period. (b) Correlations of the OA sources with their external tracers. Grey points are relative to periods considered as special events and were not considered for the linear fits. Note: All data was averaged to 30 minutes resolution, for which the separation $\mathrm{eBC}_{\mathrm{tr}}$ and $\mathrm{eBC}_{\mathrm{wb}}$ was possible. 


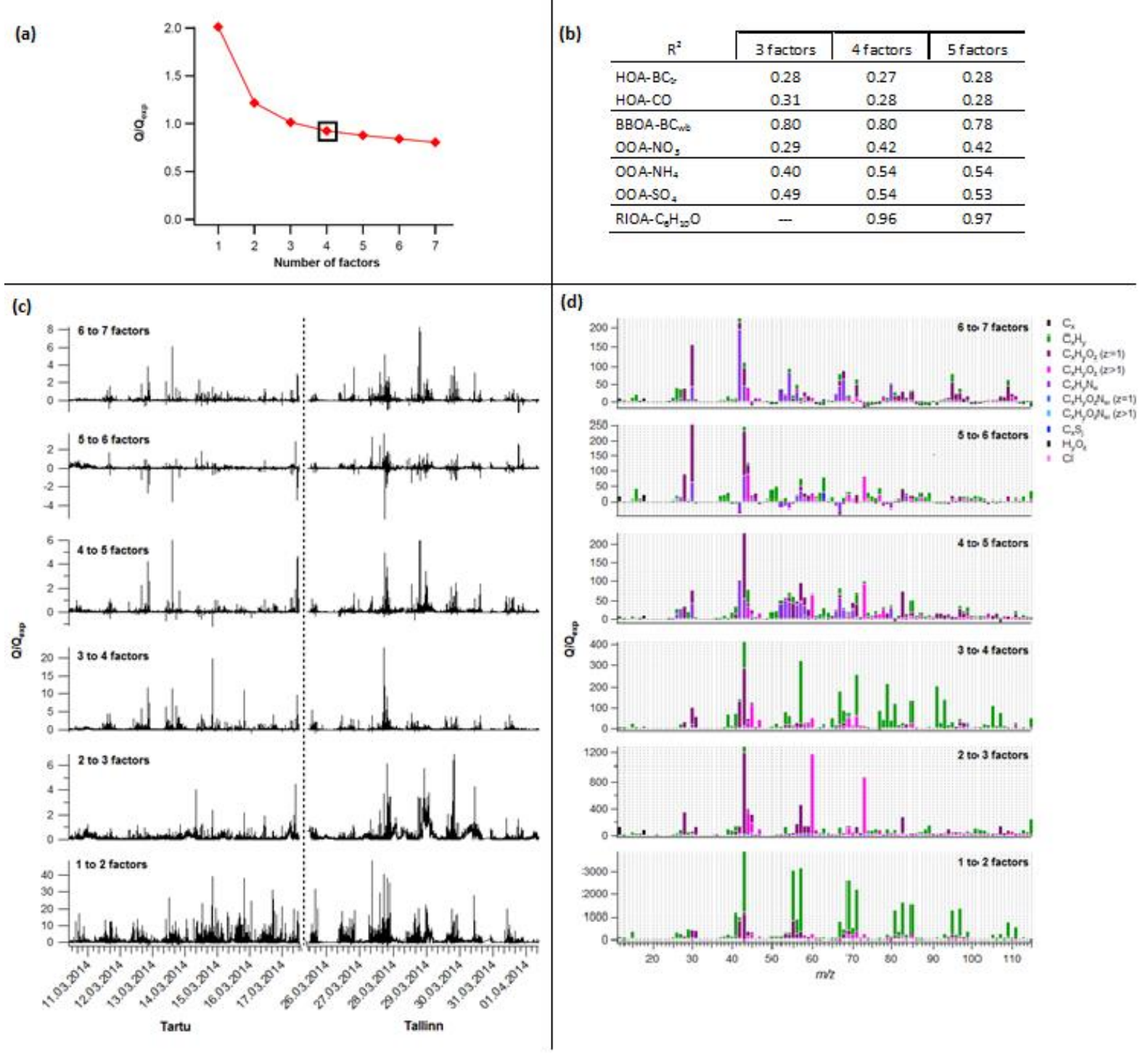

Figure S5: Source apportionment diagnostics for increasing number of factors: (a) $Q / Q_{\text {exp }}$; (b) Correlation coefficient $\left(R^{2}\right)$ between OA sources and external factors; (c) Decrease in $Q / Q_{\text {exp }}$ time series; (d) Decrease in $Q / Q_{\text {exp }}$ profiles. 


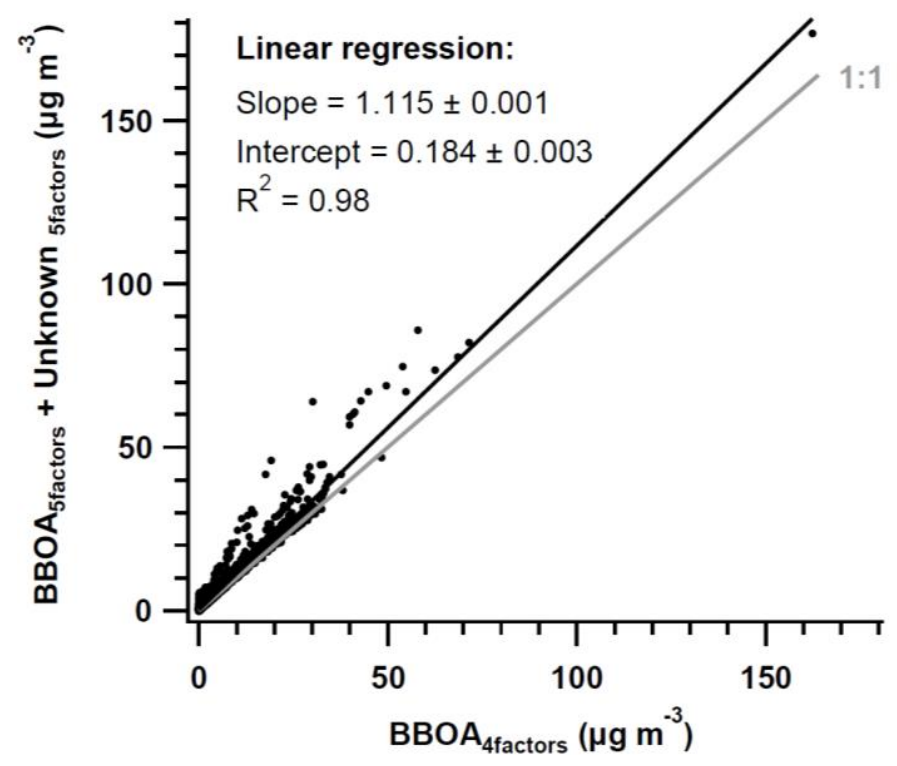

Figure S6: Correlation between the BBOA time series from the four-factor solution and the sum of the BBOA and the 'unknown' time series in the five-factor solution. 
3 factors

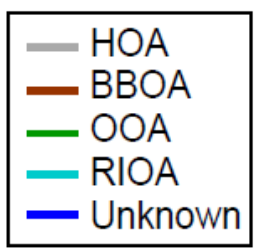

4 factors

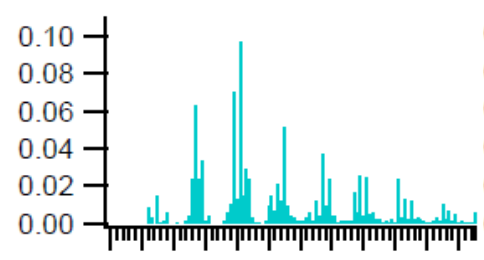

5 factors
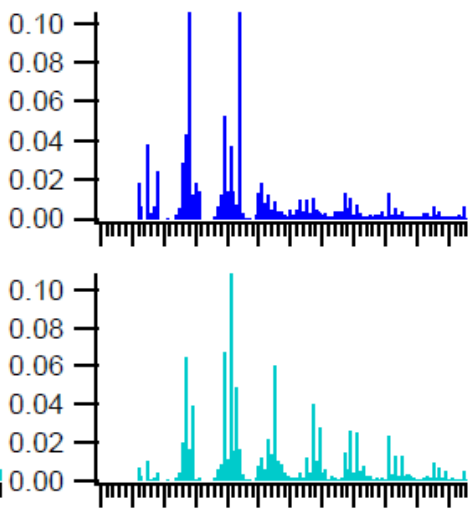
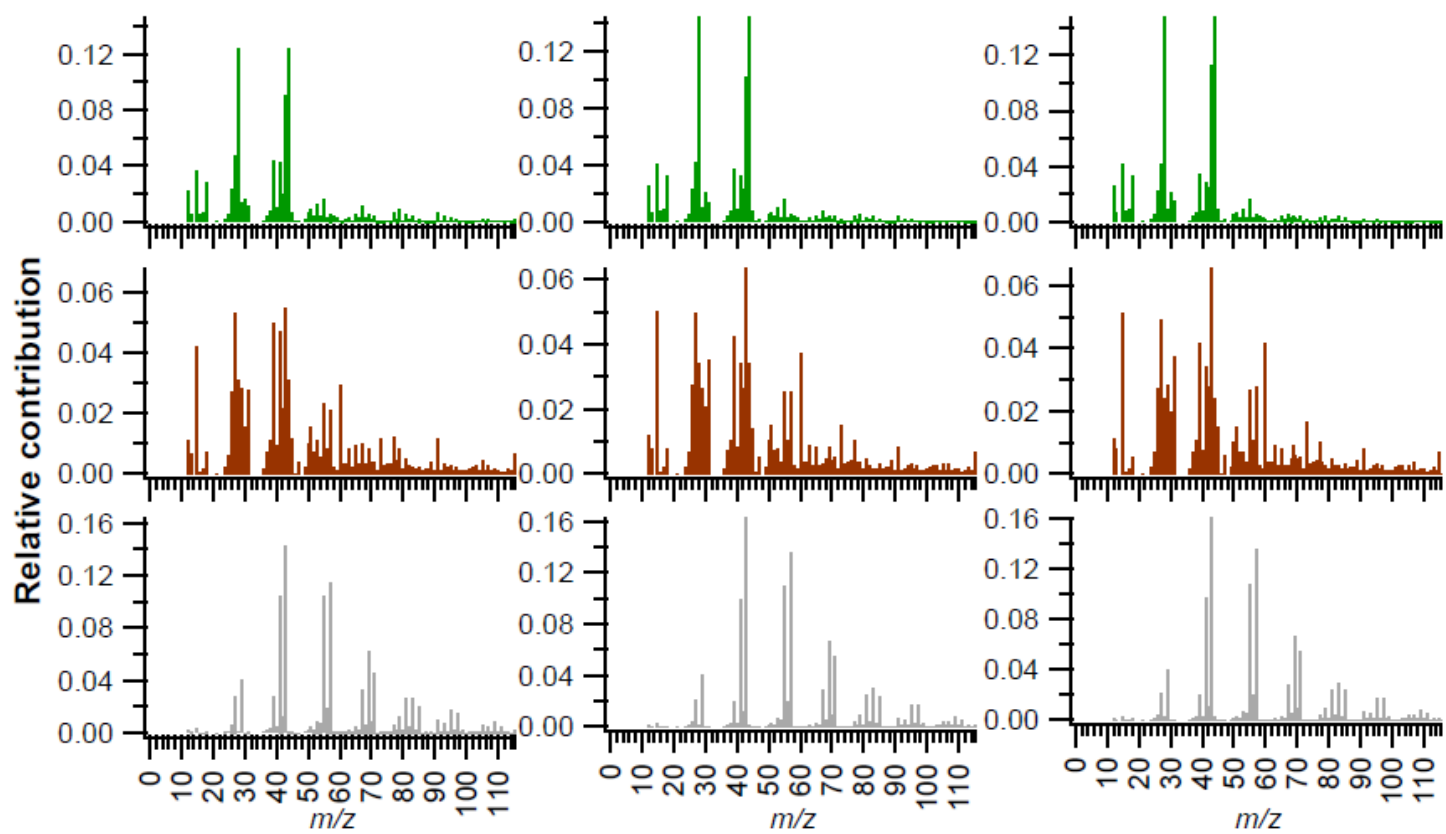

Figure S7: PMF factor mass spectra for three-, four- and five-factor solutions (from left to right). 
3 factors

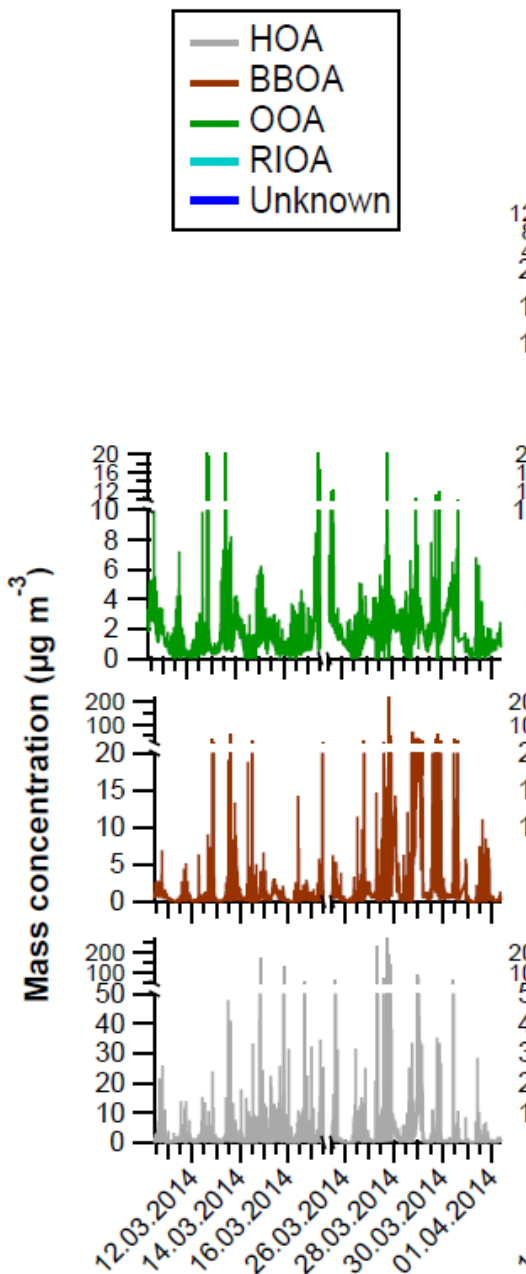

4 factors
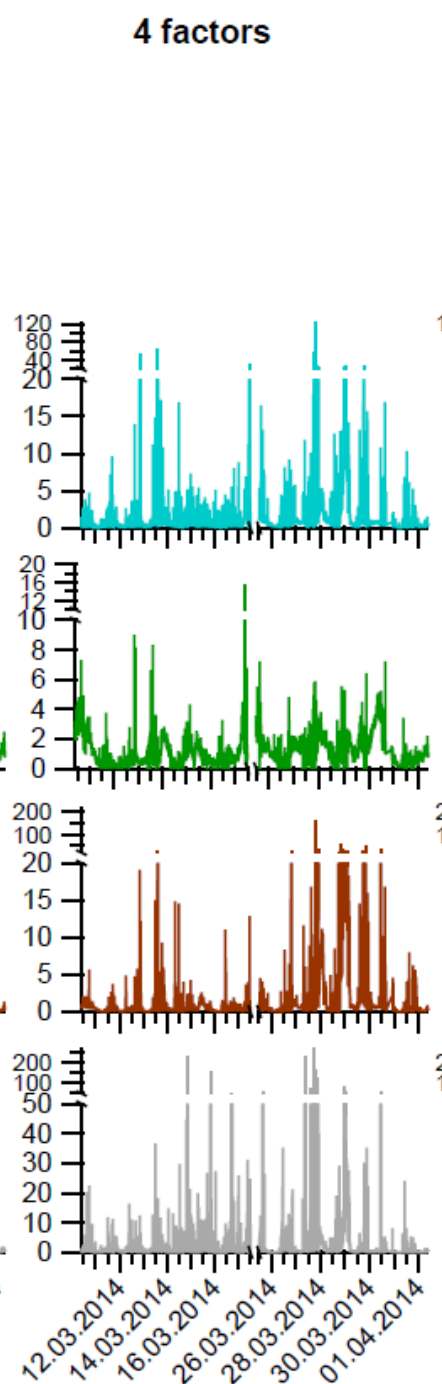

5 factors
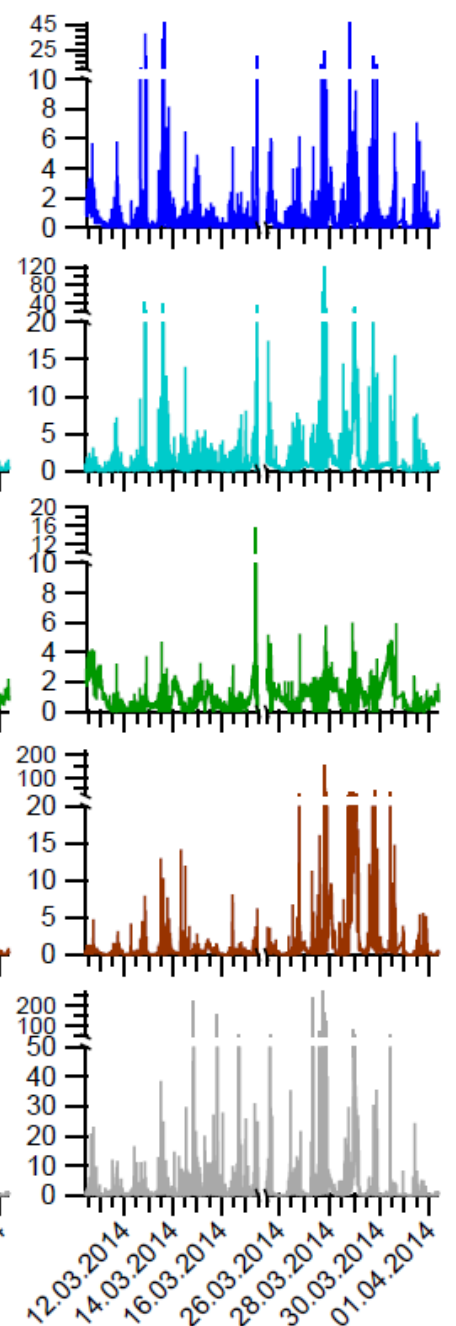

Figure S8: PMF factor temporal evolution for three-, four- and five-factor solutions (from left to right). 


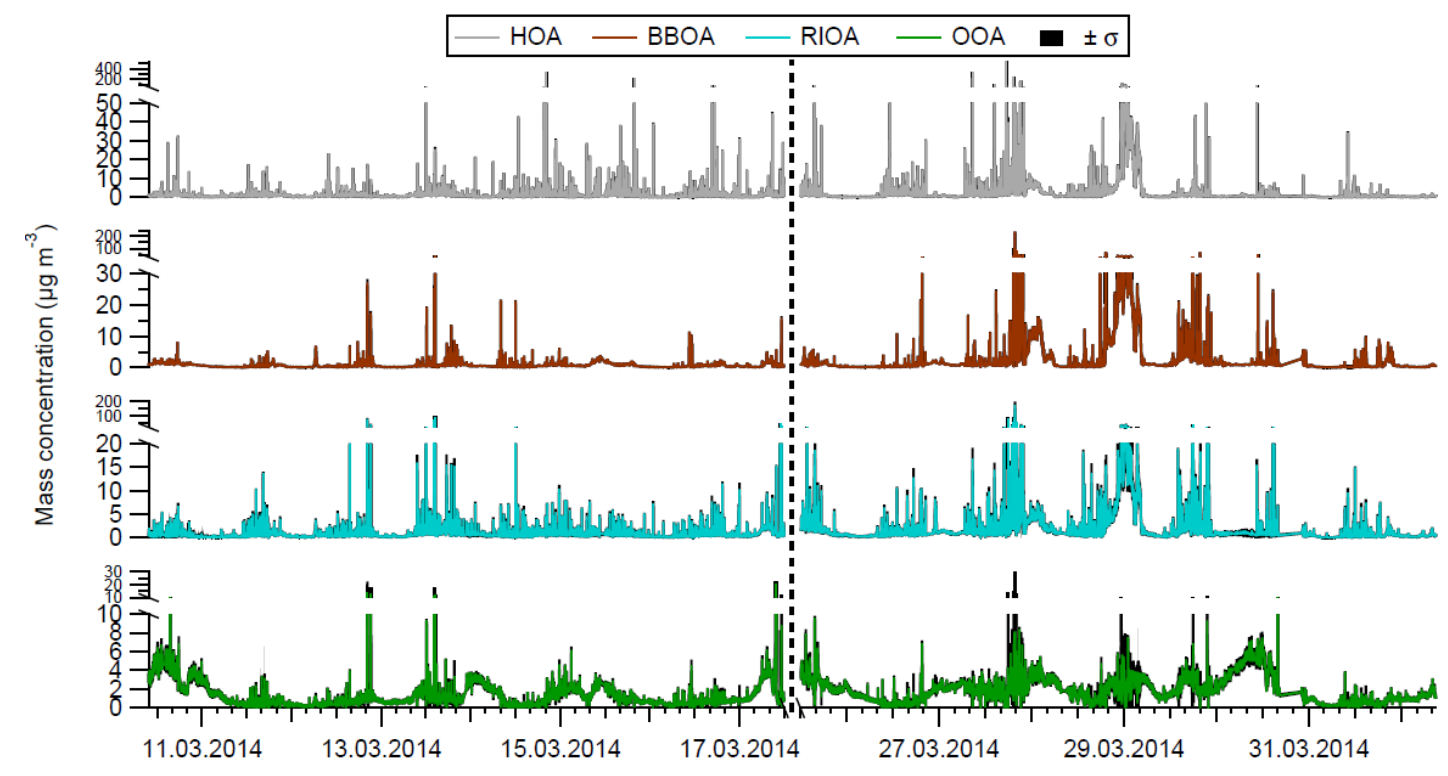

Figure S9: Temporal evolution of mass concentration of the four identified OA sources over the full measurement period. Black shaded area represents the standard deviation among 100 bootstrap runs. 

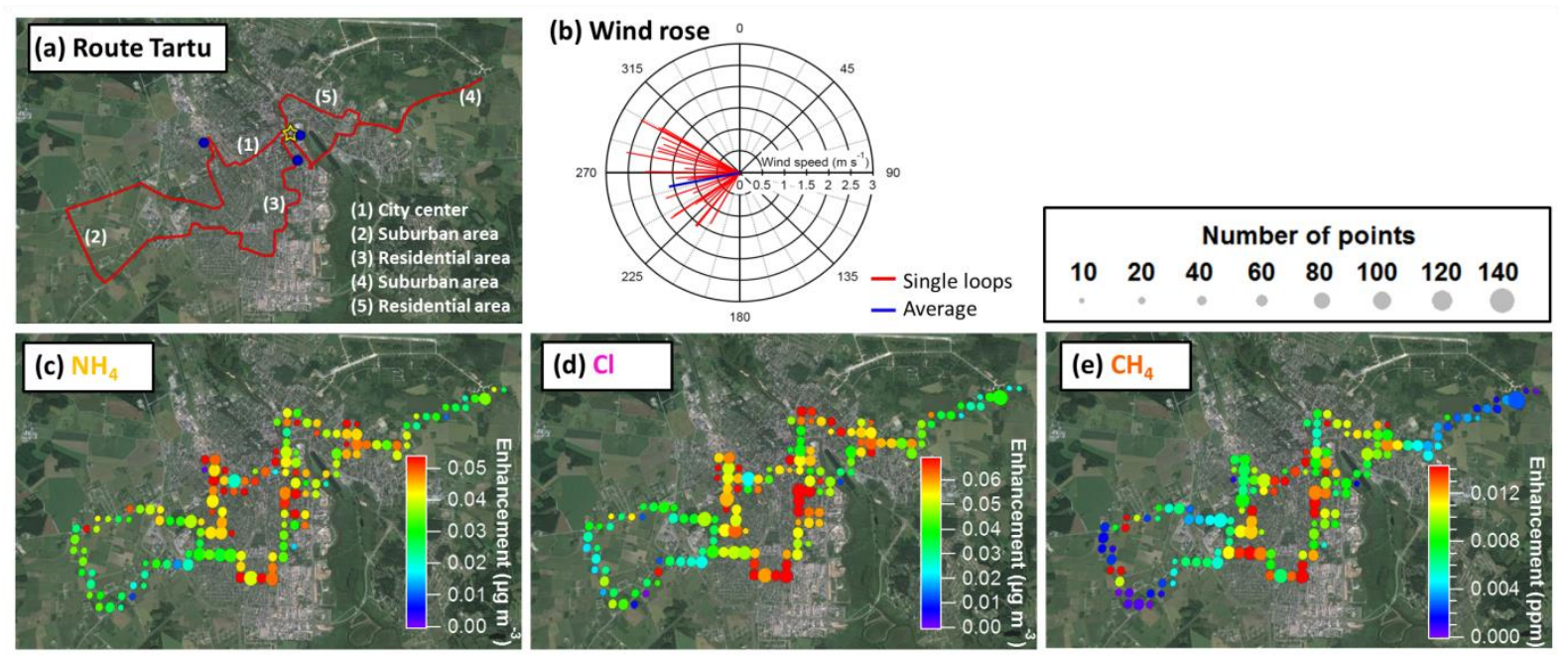

Figure S10: Average spatial distributions of (a) $\mathrm{NH}_{4}$, (b) $\mathrm{Cl}$ and (c) $\mathrm{CH}_{4}$ in Tartu. The color scales represent enhancement over the background concentrations; the maximum have been fixed to the $75^{\text {th }}$ percentile of the average enhancement of each component. The sizes of the points represent the number of points that have been averaged in each case. 


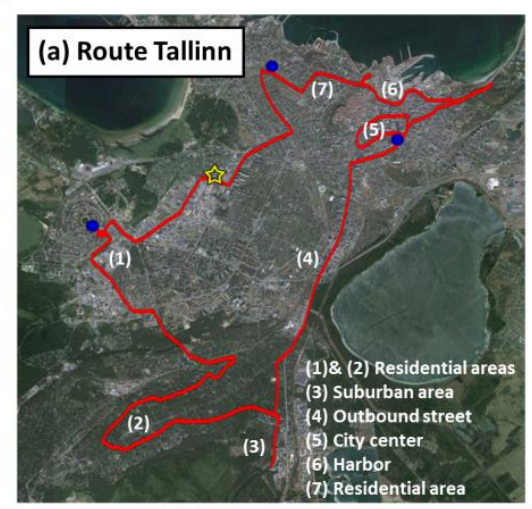

(b) Wind rose
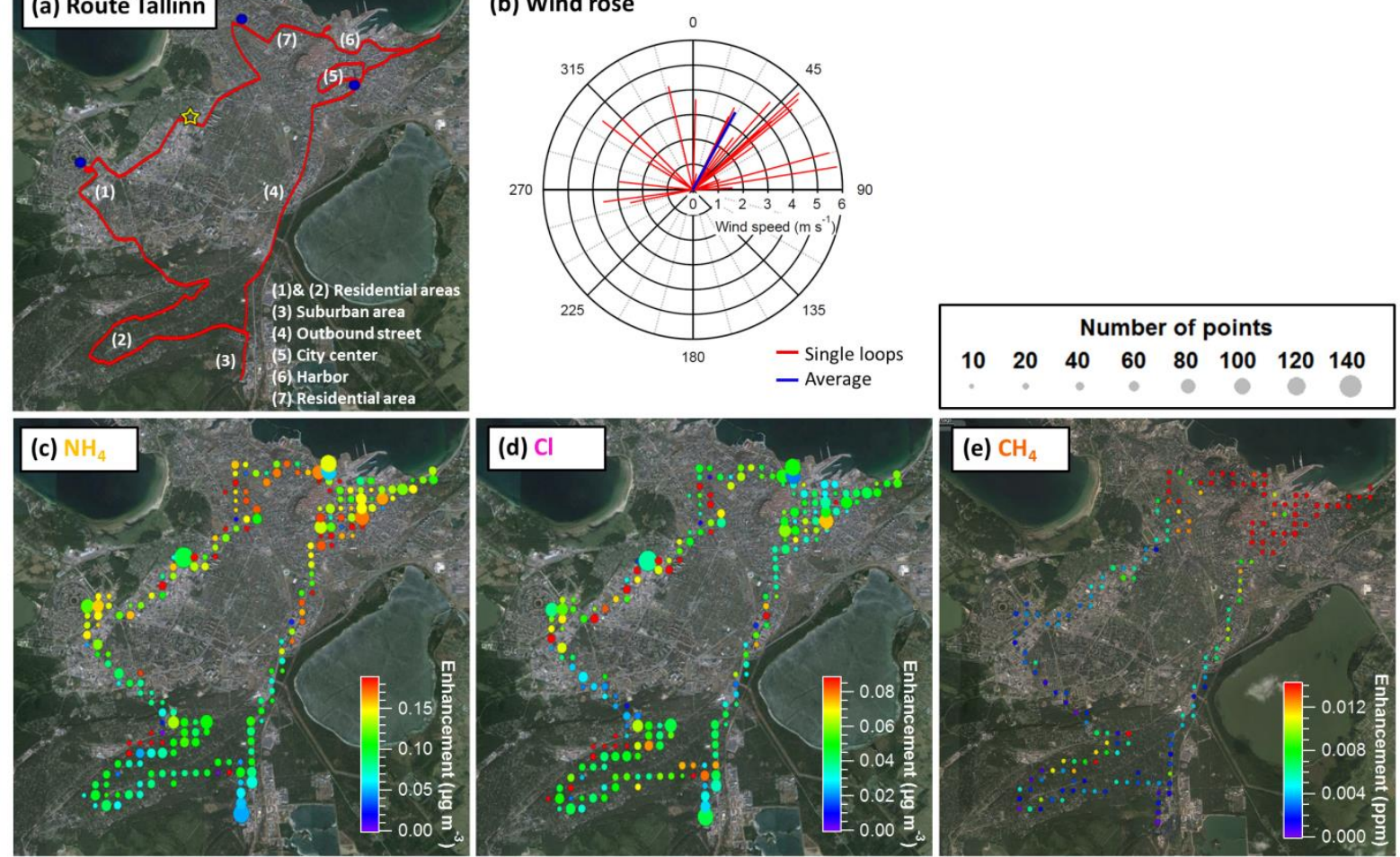

Figure S11: Average spatial distributions of (a) $\mathrm{NH}_{4}$, (b) $\mathrm{Cl}$ and (c) $\mathrm{CH}_{4}$ in Tallinn. The color scales represent enhancement over the background concentrations; the maximum have been fixed to the $75^{\text {th }}$ percentile of the average enhancement of each component. The sizes of the points represent the number of points that have been averaged in each case (Note: less data available for $\mathrm{CH}_{4}$ ). 

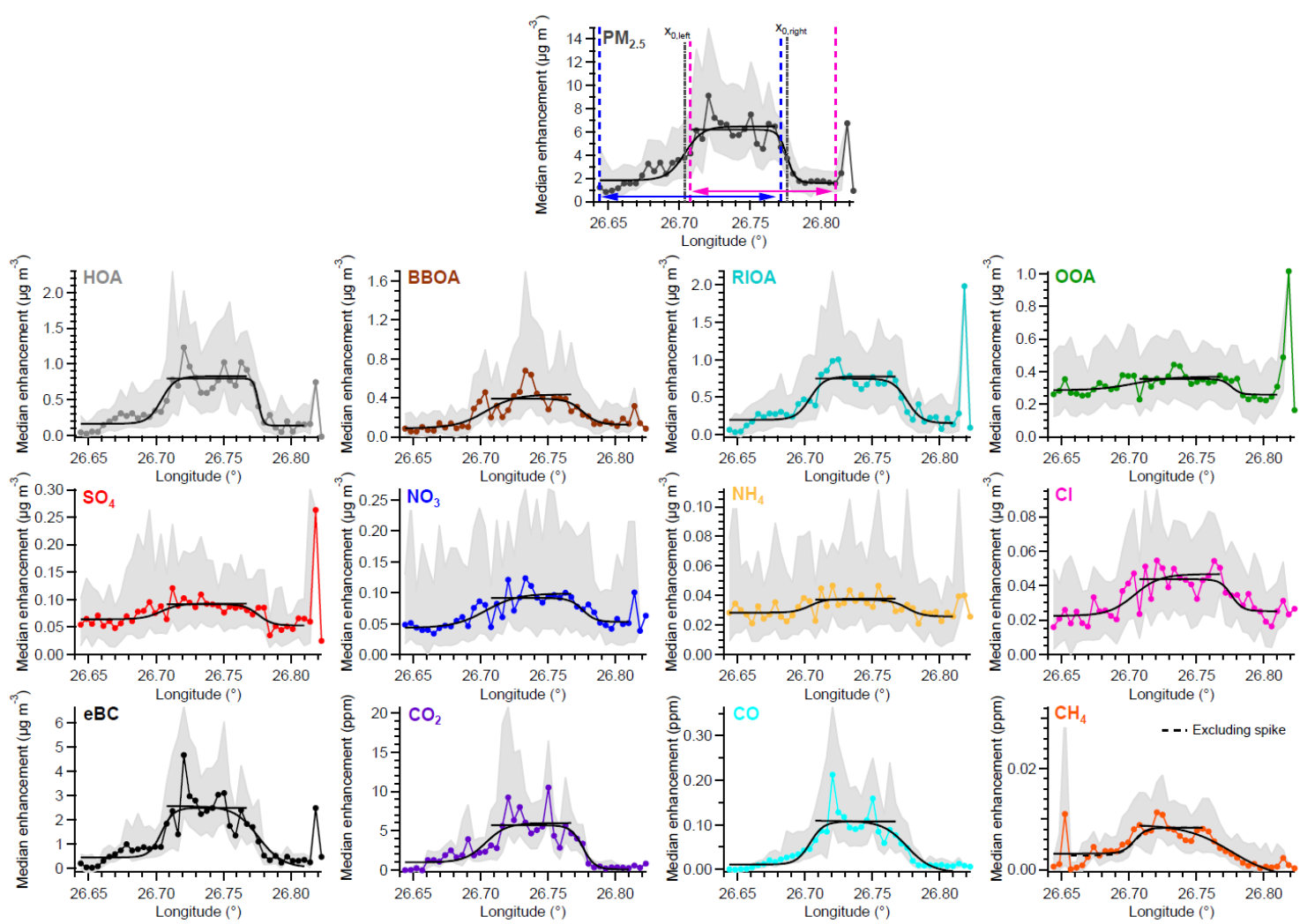

Figure S12: Median longitude profiles of the enhancements of all measured components and sources in Tartu. Colored curves represent the median enhancement of each component/ source over 26 loops and the grey shaded area represents the first and third quantiles (Q1 and Q3). The median enhancements were fitted with sigmoid functions (black curves). The fitting limits (pink and blue arrows in top panel) and the sigmoid's midpoint $\left(\mathrm{X}_{0}\right)$ were determined from the fit of the total $\mathrm{PM}_{2.5}$ mass $\left(\mathrm{NR}-\mathrm{PM}_{2.5}\right.$ plus $\left.\mathrm{eBC}\right)$ and then imposed to the other components/sources. The dashed black lines indicate a non-standard fit (described in each case in the plot) and the results of these fits are represented in parenthesis and grey color in Table 2b. Notes: The spike found in the east for RIOA, OOA and $\mathrm{SO}_{4}$ is not representative, as it is related to one single measurement point. The spike in $\mathrm{CH}_{4}$ in the west side is related to consistent increases of this component nearby a cowshed and will be further investigated in a future publication. 


\section{Tartu}
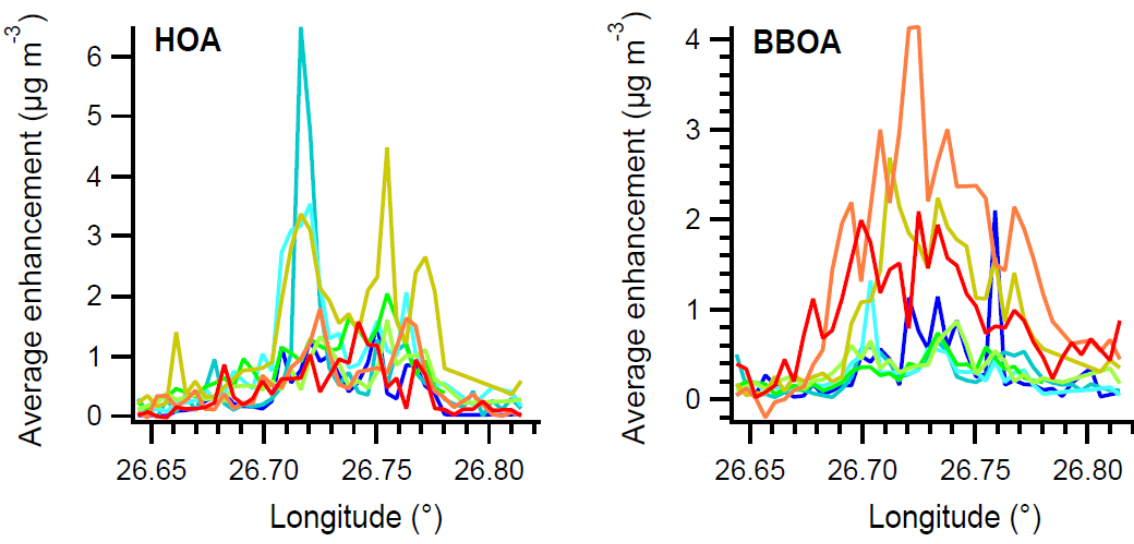

Time (hh:mm, LT):
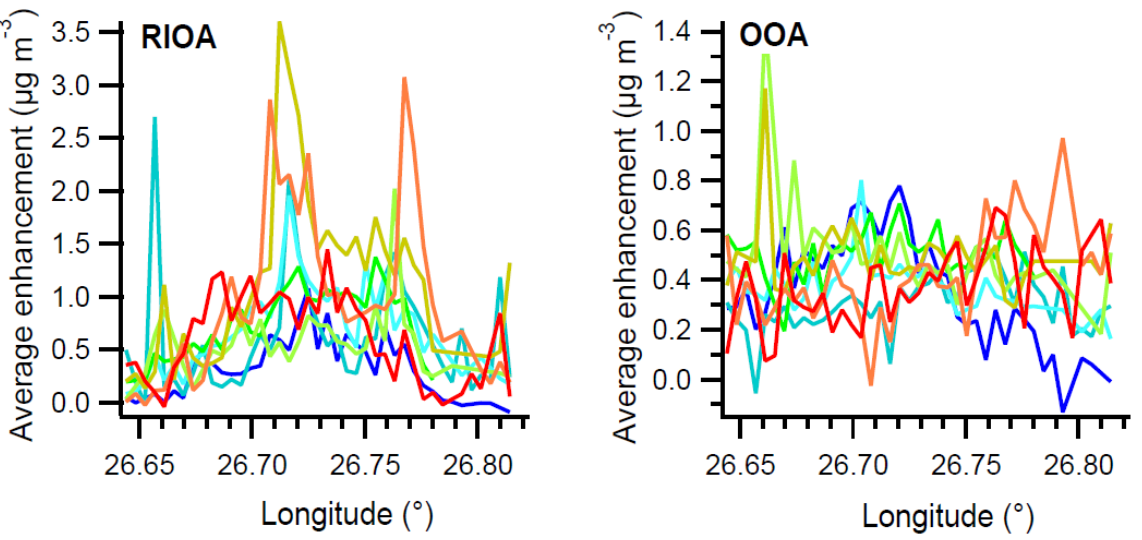

Figure S13: Average longitude profiles of the enhancements of the OA sources in Tartu separated into time-bins of two hours of local time (LT). 


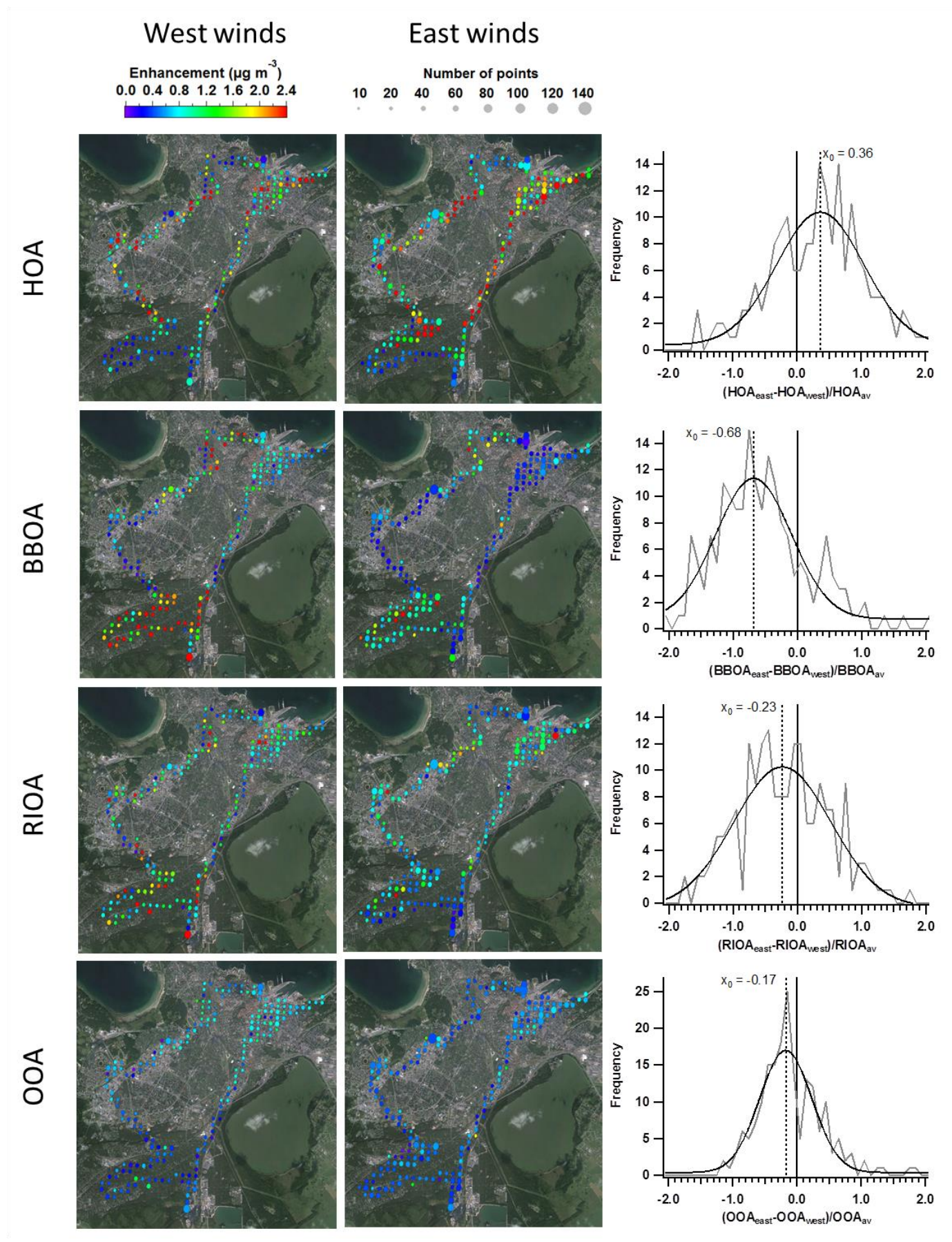

Figure S14: Left: Average spatial distributions of the OA sources in Tallinn for west and east winds. The color scale represents the enhancement over the background concentrations and the sizes of the points represent the number of points that have been averaged in each case. The data related to special events is not considered. Right: Distribution of the normalized differences between the east- and west-related spatial distributions for each compound. $\mathrm{X}_{0}$ indicates the center of the gauss function used to fit each distribution. 


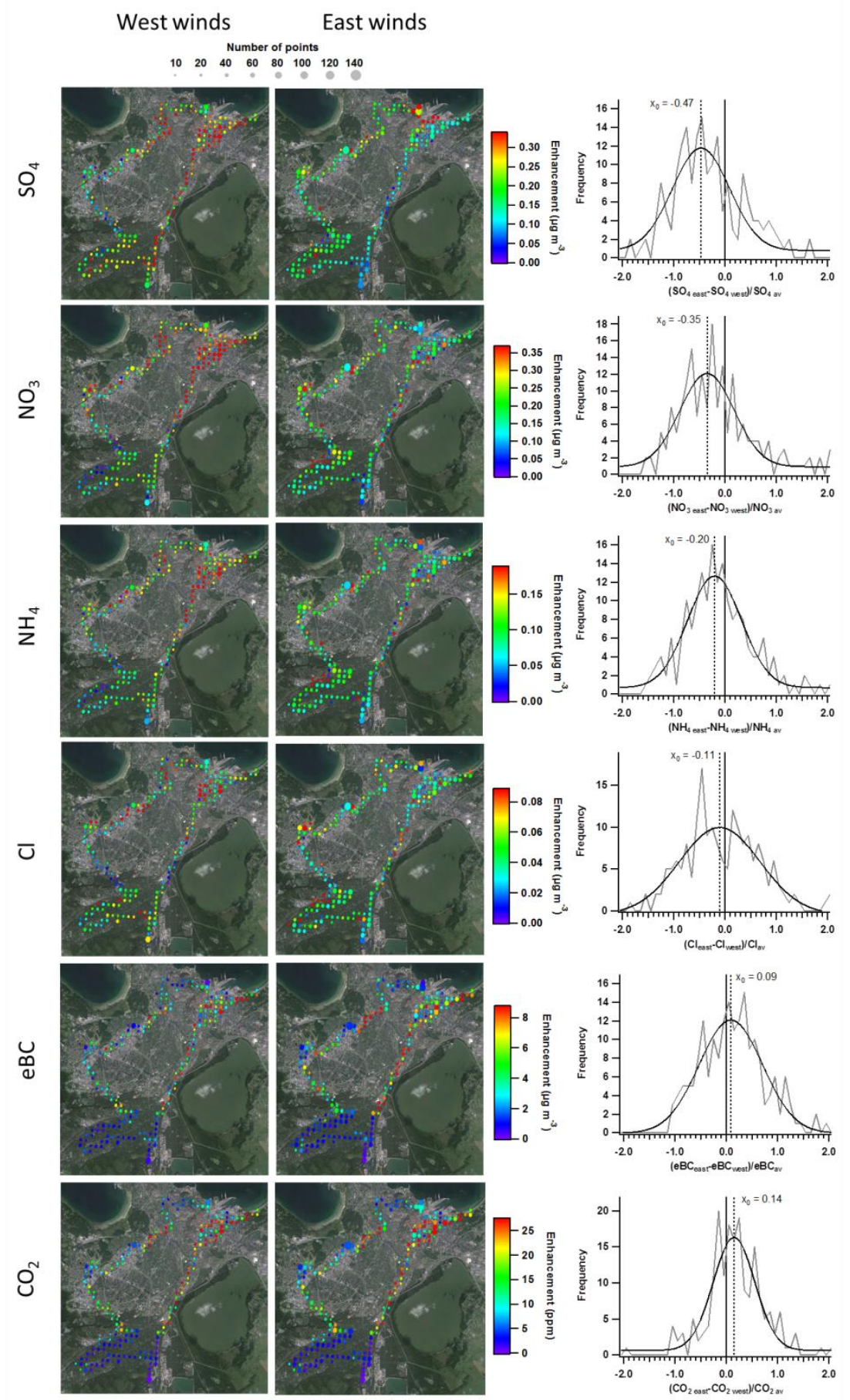

Figure S15: Left: Average spatial distributions of the inorganic components $\left(\mathrm{SO}_{4}, \mathrm{NO}_{3}, \mathrm{NH}_{4}\right.$ and $\mathrm{Cl}$ ), eBC and $\mathrm{CO}_{2}$ in Tallinn for west and east winds. The color scales represent the enhancement over the background concentrations and the size the number of points that have been averaged in each case. The data related to special was excluded for these analyses. Right: Distribution of the normalized differences between the east- and west-related spatial distributions for each compound. $\mathrm{X}_{0}$ indicates the center of the gauss function used to fit each distribution. 


\section{References:}

Zotter, P.: Sources of fossil and non-fossil atmospheric aerosols, Ph.D. thesis, Eidgenössische Technische Hochschule, ETH Zürich, Switzerland, 2015. 